\title{
Analysis and Reflection on the Utilization of Foreign Academic E-Book-An Empirical Study Based on 367 Users of a University
}

\author{
Jiayin Liu' ${ }^{1}$ Chen Chen ${ }^{2}$ \\ ${ }^{1}$ Library, Nanjing University of Aeronautics and Astronautics, Nanjing, China \\ ${ }^{2}$ Institute of Scientific and Technical Information, Nanjing University of Aeronautics and Astronautics, Nanjing, China \\ Email: ljylib@nuaa.edu.cn, chenchen_nuaa@163.com
}

How to cite this paper: Liu, J.Y. and Chen, C. (2018) Analysis and Reflection on the Utilization of Foreign Academic E-Book-An Empirical Study Based on 367 Users of a University. Open Access Library Journal, 5: e4500.

https://doi.org/10.4236/oalib.1104500

Received: March 12, 2018

Accepted: April 9, 2018

Published: April 12, 2018

Copyright $\odot 2018$ by authors and Open Access Library Inc.

This work is licensed under the Creative Commons Attribution International License (CC BY 4.0).

http://creativecommons.org/licenses/by/4.0/

\begin{abstract}
Based on the form of questionnaire, this paper explores the use of foreign academic e-books by teachers and students in a certain school from a subjective view. 367 Users' behavior, habits and needs were analyzed. Based on the results of the analysis, four suggestions are put forward to improve the overall utilization: Promote the localization of interface, pay attention to users' advice while purchasing, improve content disclosure and subject classification, and guide users to have social sharing.
\end{abstract}

\section{Subject Areas}

Artificial Intelligence, Education, Information and Communication, Security, Privacy, Trust, Information and Communication Theory and Algorithms, Online Social Network Computing

\section{Keywords}

Questionnaire Investigation, E-Books of Foreign Languages, Use Evaluation, Behavior Analysis

\section{Introduction}

With the progress of science and technology and the development of the society, university libraries are also experiencing a new transformation and upgrading, digital resources construction and information services are also facing more problems and challenges. E-books, especially academic e-books in foreign languages, have become a new hot point of construction [1]. Formulating a more reasonable purchase plan, and improving the utilization level of existing collections, we 
need to overall analyze the utilization of purchased books from various angles.

At present, some scholars have conducted research on this aspect. The research of Anuradha K T and Usha H S. shows that the readers' most dissatisfaction with e-books is the incompatibility between databases, and the inconsistency between paper books and e-books. However, it is relatively satisfied that the e-book can be accessed remotely and without copy restrictions [2]. Levine-Clark M's research shows that the most unsuitable place for readers in e-books is the inconvenience of screen reading [3]. Roesnita I and Zainab A N have studied undergraduates' cognition of e-books. The results show that most students' understanding of e-book is more content rather than carrier, and nearly half of the students get the resources from the school library website, which is positive for the convenience of online access [4]. Rowlands I's research shows that most readers are relatively savvy about e-books [5]. Littlewood $\mathrm{H}$ compares the cost of using e-books with paper books [6]. Chiun Sin Lin, from the perspective of recommendation influence, discusses the impact of word-of-mouth, advertising and expert recommendation on e-book usage intention. The results show that word of mouth is more important than other suggestions in determining the willingness to use academic e-books. Increasing trust and reducing the risk of use can regulate the relationship between the recommended sources and the behavioral intentions of the use of e-books [7].

Based on the previous research, this paper proposes an empirical study to improve the utilization of foreign academic e-books.

\section{Questionnaire Design and Survey Process Description}

\subsection{Questionnaire Design}

The questionnaire is divided into four parts, which are filled out by secret ballot:

1) The first part is the user's basic situation survey. It includes three parts: gender, identity and research field.

2) The second part is the investigation of personal literacy information. It includes the understanding of school electronic database, the understanding of e-books, the level of retrieval and the level of foreign language.

3) The third part is a survey of the user behavior and habits. It includes: The frequency of using e-books, the ways to know academic e-books, the common used database of academic e-books of foreign languages, the main use habits, reading habits, attitudes towards paper books and e-books, and factors to influence their use were investigated.

4) The fourth part is about the use of demand questionnaire. Eight characteristic factors were comprehensively selected.

\subsection{Survey Implementation}

Take the random sampling and random distribution methods, through the form of network questionnaires to distribute and recycle. Besides sending questionnaires through social networks, we also carry out propaganda and retransmis- 
sion in the student community of the school's colleges.

According to statistics, a total of 387 questionnaires were collected from the survey. After screening, 20 invalid, and 367 effective questionnaires were available. The effective rate of the questionnaire was $94.8 \%$, and the sample quantity and effective rate all meet the requirements of statistical analysis.

\section{Analysis of Questionnaire Survey Results}

\subsection{User Feature Analysis}

Statistics on the source of surveyed users, among the 367 users surveyed, boys accounted for $57.22 \%$ and girls accounted for $42.78 \%$.

According to the statistics of the surveyed users' identity, master degree and doctor degree occupied a large proportion, followed by undergraduates, reaching $22.34 \%$, and the percentage of teachers occupying the least was only $8.17 \%$.

The research field of the surveyed users was counted, and the engineering background user reached $67.57 \%$. Another 12 users chose other subjects.

Then the author conducted a simple understanding of the information literacy of the whole surveyed group. According to statistics, $43.32 \%$ of respondents understand the advanced search, and can basically meet their requirements for information retrieval, $22.89 \%$ having get trained who can fully meet their retrieval requirements and the remaining $1 / 3$ of the users have low retrieval level, who can't have complete and accurate retrieval.

Nearly $70 \%$ of the respondents were proficient or fluent in foreign languages. However, it should be pointed out that most of the users are still resistant to foreign languages, including foreign literature and foreign language platforms. One reason is that this is a dependence on mother language. On the other hand, it also shows the necessity of localization for database platform interface.

Based on the above analysis of the user characteristics, we consider that the survey sample is true and reliable, in line with the actual situation of the school, which can conduct relevant analysis.

\subsection{Basic Information Analysis}

On the basis of the analysis of user characteristics, the author analyzes the basic information of the surveyed users, mainly analyzes the user's knowledge of foreign language academic e-books, their frequency of use, types of use, and factors that influence their use.

1) Cognitive analysis

Statistics show that most users have used all kinds of electronic resources in schools, as well as e-books, but users who use foreign academic e-books are only $70.3 \%$, which is less popularization than the first two items. This shows that teachers and students do not know enough about this type of resources, also because of the relatively professional content in this area. For undergraduates and some master degree students, it is not the main knowledge source of learning and scientific research. 
The statistical results show that the most common three sources are the recommendation of specialized teachers and students, the citation reference when reading the professional literature and the auxiliary discovery when searching for them. But users through the library and the subject librarian's guide as well as the database merchant's propaganda to know and use the source are not many. This reflected that the promotion of the library and the database merchant in this kind of resources still needs to improve.

2) Utilization frequency analysis

The frequency of use of academic e-books in foreign languages is different in different fields of identity and research. According to statistics of cross tabulation statistics of identity and research area and frequency of utilization, nearly $50 \%$ of teachers and students use foreign academic e-books every week, nearly $70 \%$ of teachers and students use monthly, indicating that foreign academic e-books are important research references for teachers and students.

Students of master degree and doctor degree and teachers are highly frequent use groups, especially doctoral students, whose proportion of using e-books is $73.8 \%$ per week. This result is very consistent with identity traits. Students of master degree and doctor degree, especially Ph.D., who are in the golden stage and critical period of scientific research. The utilization frequency of teachers is also very high, and the overall utilization of undergraduate students is relatively low.

In terms of research area, science majors have the highest frequency for the use of foreign academic e-books, which has reached $64.4 \%$ per week, while engineering majors have reached $47.8 \%$. This indicates that science and engineering majors' demand for foreign academic e-books is relatively strong. Arts majors also have a certain frequency of utilization. It should be noted that other majors, including arts and some interdisciplinary majors, also have a greater need for foreign books, but due to the samples limit of this part, the truth of the situation needs further verification.

3) Utilization type analysis

According to the research field and the mainly use of electronic resources and the mainly use of foreign e-book database, we made cross-tabulation. The results show that journal papers, dissertations and e-books are the most widely used literature types in different major research fields. Conference papers and scientific and technological reports are more used in science and engineering majors, but less in the use of patent standards. This is also consistent with the guarantee priority of various types of documents in the library.

In terms of the types of foreign e-book databases, the use of the three comprehensive databases, Elsevier, Springer, are the most, which is consistent with the previous data survey. In the field of professional database, IEEE and AIAA are the most used in science and engineering majors, which is consistent with the distribution of special majors in the school.

4) Analysis of factors affecting Utilization 
According to the statistical results, inconvenient download of full text, lack of retrieval methods and skills, and unfamiliar with the types and contents of database are the three most prominent factors.

\subsection{Analysis of Behavior Habits}

1) Use behavior analysis

From the access to the database, access to e-books, reading habits, note-taking habits, and the use of citation tools to conduct user behavior analysis.

Library catalog, unified retrieval platform and Google academic are the most commonly used ways of access. Google academic search is more convenient to access, and sometimes can obtain the full text which can't find in library catalogue. Overall, there is no big difference in access ways.

In terms of obtaining ideas, most of the teachers and students have a general research direction first, and then search to obtain. At present, the construction of the subject classification catalogue of libraries and database needs to be improved, which cannot provide good guidance and clues that need to be strengthened.

In reading habits, $78.1 \%$ of the users are used to downloading and then read, which is also the continuation of the paper book habit.

In the habit of taking notes, $55.04 \%$ of the users have been used to electronic notes. Compared to reading, users are more receptive to e-notes than while in reading, which can also inspire the database platform providers. If you can integrate note-taking functions and complete online reading, note-taking, collection, synchronization of the entire process, the rate of online reading should be increased.

SCOPUS and BKCI are more authoritative book citation tools; the current users are not in a big quantity. One reason is that the use of books and periodicals is different in setting and purpose; another reason is, libraries need to strengthen guidance, let more users know these tools, so that users can easily locate the frontiers and hot topics of the subject.

2) Paper electric attitude analysis

Through the questionnaire to understand whether there are differences in the attitudes of users of different identities and disciplines to paper books and e-books, and whether there is a correlation between the two kinds of books. In order to verify these two hypotheses, the attitudes of paper books and e-books with different identities and disciplines are cross-tabulated, and chi-square tests are taken.

The results showed that, regardless of identity differences, users prefer paper books. Among them, undergraduate and doctoral students have the highest acceptance to e-books. Undergraduates are younger and accept new things more quickly. Doctoral students have a wide range of reading, but many books are not in paper, which make their acceptance and preference also increased. The chi-square test results show that the progressive bilateral sig value is 0.016 , indicating that the attitude to paper books and e-books is related to identity, and the 
attitudes of different identities have significant differences, which verifies the above hypothesis.

Teachers and students of science majors have a preference for e-books, while students from engineering and liberal arts majors prefer paper books, which is different from traditional ideas. But overall, regardless of major differences, most teachers and students prefer paper books. Chi-square test results show that the progressive bilateral sig value is 0.006 , indicating that the attitude to paper books and e-books is significantly related to the research field, and different research areas have different attitudes to paper books and e-books.

3) An Analysis of the relationship between Reading habits and Reading experiences

Divide the reading habits into three categories, quickly browse online reading, selective key chapters reading, and download full-text reading. The reading experience is divided into two aspects, quality and speed, and subdivided into five situations.

$42.5 \%$ of the people think that reading e-books result the higher reading speed than reading paper books, but the reading quality reduced. However, in terms of subdividing, nearly half of the teachers and students who read online have felt the improvement of their reading speed and quality. This shows that the choice of reading style has no obvious influence on the reading experience despite the inherent psychological habits. The e-book database mostly takes the method of the chapter to download, which indicates that download to read after overviewing the catalogue is a reading way in essence. These users still feel that the quality of reading decreased while the reading speed improved.

\subsection{Utilization Needs Analysis}

Through the statistics of the total needs of users, the differences between different users' needs are analyzed.

1) General demand analysis

Through the descriptive statistical analysis of the characteristic factors, we can see that the demand of each factor has not big difference. The average value of resources quantity and full-text downloading are relatively large, which indicates that teachers and students have a big demand for resources and full-text downloading of academic e-book databases of foreign languages. The average value of social sharing is the lowest, which indicates that teachers and students have the least demand for social sharing of academic e-book database of foreign language. The results are sorted as: The number of resources $=$ full text download $>$ update speed $>$ retrieval methods $>$ Citation Analysis $>$ localization degree $>$ interface interaction $>$ social sharing.

2) Analysis of different users' needs

In order to understand the difference of the demand of different users on these eight characteristic factors, the single factor variance test of different identity and research field is carried out respectively to explore what needs are consistent, what are significantly different and what are the demand influence of dif- 
ferent user identities and research areas among the significant difference under the effect of eight characteristic factors in the academic e-book database of foreign language.

Take single factor variance test (one-way ANOVA) to analyze the differences of different identities in different use requirements. The results showed that the sig of $\mathrm{F}$ test was less than 0.05 on the three aspects: full text download, citation analysis and social sharing, indicating that under the significant 0.05 , different identities have big significant differences in citation analysis and social sharing needs in downloading full-text, but no significant differences in other needs. After the multiple comparison, we can see that the demand of undergraduate students is significantly smaller than that of doctoral students; In citation analysis, the demand of undergraduate students is significantly larger than that of master students, whose demand is significantly smaller than that of doctoral students, and the demand of teachers is significantly smaller than that of undergraduates, master students and doctoral students. In terms of social sharing needs, teachers' needs are significantly smaller than that of undergraduates, master's students and doctoral students.

Same way to take single factor variance test (one-way ANOVA) to analyzes the differences in the use needs of students in different fields of study.

Only in citation analysis and social sharing, the sig of $\mathrm{F}$ test was less than 0.05 in different research areas, which indicated that under the significant 0.05 , there were significant differences in citation analysis and social sharing between different research fields. There is no significant difference in other demands. After the multiple comparison, we can see that in the citation analysis demand, the demand for engineering majors is significantly smaller than the liberal arts majors; In terms of social sharing needs, the demand for engineering majors is significantly smaller than that for liberal arts majors and science majors.

\section{Conclusions and Prospects}

From the subjective perspective view to do the questionnaire survey of teachers and students' use of foreign academic e-books, the use of behavior and habits, and the use of demand. The origin and information literacy of users are analyzed. To know teachers and students' cognition on the foreign academic e-book database, use frequency, use type, factors to influence their use, this paper analyzes the relationship of their attitude to e-book and paper book, reading habits and reading experience, and quantifies the differences of users' needs in different levels and subject backgrounds. The main conclusions are as follows:

1) Users still have resistance to foreign language content; improving the localization level of platform interface can improve the utilization rate to a certain extent.

2) The overall utilization is good, students of science and engineering majors and students with master and PHD degree are the main use group, but most of the information sources are from their own searching or teachers or students recommendation. The library does not serve as a referral service, and users' demand should be consulted more when purchasing resources. 
3) Optimizing the purchasing structure and improving the retrieval level of users should be the next work direction of the library. The database providers also need to provide training to improve the content disclosure and subject classification of their own platform.

4) Users generally do not have the will to share subject content and exchange academic experience through database platform, which weakens the sharing and diffusion of knowledge and academic influence of scholars on the network to a certain extent, which requires further guidance.

\section{Acknowledgements}

This work was funded by the Project of Philosophy and Social Science of Universities in Jiangsu Province (2014SJD051) and the Fundamental Research Funds for the Central Universities (NR2014048).

\section{References}

[1] Top Tech Trends-2017 Annual. American Library Association, 2017-06-25 [2017-07-07]. http://www.ala.org/lita/ttt

[2] Anuradha, K.T. and Usha, H.S. (2006) Use of e-Books in an Academic and Research Environment: A Case Study from the Indian Institute of Science. Program, 40, 48-62. https://doi.org/10.1108/00330330610646807

[3] Levine-Clark, M. (2006) Electronic Book Usage: A Survey at the University of Denver. Portal: Libraries and the Academy, 6, 285-299. https://doi.org/10.1353/pla.2006.0041

[4] Roesnita, I. and Zainab, A.N. (2013) The Pattern of E-Book Use amongst Undergraduates an Malaysia: A Case of to Know is to Use. Malaysian Journal of Library \& Information Science, 10(2).

[5] Rowlands, I., Nicholas, D., Jamali, H.R., et al. (2013) What Do Faculty and Students Really Think about e-Books? Aslib Proceedings New Information Perspectives, 59, 489-511.

[6] Littlewood, H., Hinze, A., Vanderschantz, N., et al. (2014) A Log Analysis Study of 10 Years of eBook Consumption in Academic Library Collections. The Emergence of Digital Libraries-Research and Practices. Springer International Publishing, 1250-1256.

[7] Lin, C.-S., Tzeng, G.-H., Chin, Y.-C., et al. (2010) Recommendation Sources on the Intention to Use e-Books in Academic Digital Libraries. Electronic Library, 28, 844-857. https://doi.org/10.1108/02640471011093534 